\title{
THE EXISTENCE OF PROPER SOLUTIONS OF A SECOND ORDER ORDINARY DIFFERENTIAL EQUATION
}

\author{
J. D. SCHUUR
}

We shall consider the equation

$$
\begin{aligned}
x^{\prime \prime} & =f\left(t, x, x^{\prime}\right): f(t, x, y) \text { continuous on } D \\
& =\{(t, x, y): 0 \leqq t<+\infty,-\infty<x, y<+\infty\} .
\end{aligned}
$$

We further assume: (i) $f(t, x, y)$ is such that the solutions of (1) are uniquely determined by initial conditions; (ii) $x f(t, x, 0)>0$ if $t>0, x \neq 0$; (iii) $f(t, 0,0)=0$ for all $t \geqq 0$; (iv) if $u>v$, then $f(t, u, y)$ $\geqq f(t, v, y)$, if $r>s$, then $f(t, x, r) \geqq f(t, x, s)$.

From (ii), a positive solution of (1) has no relative maxima, a negative solution has no relative minima. If $x(0)>0$ and $x(c)=0, x^{\prime}(c)<0$ for some $c>0$, then $x(t)<0$ for all $t>c$. The behavior of positive solutions and negative solutions is similar, so we shall consider only the former. If we totally disregard nonpositive solutions, we can weaken (ii) to $f(t, x, 0)>0$ for $x, t>0$.

A solution, $x(t)$, of (1) is proper if $x(t)$ exists and is positive for all $t \geqq 0$. If $f(t, x, y)$ satisfies (i)-(iv), we shall show that given $A>0$ there exists a unique proper solution of (1), $x(t)$, such that $x(0)=A$ and $x^{\prime}(t)<0$ for all $t \geqq 0$. We shall use the topological method of $\mathrm{T}$. Ważewski ([2] or [1, pp. 179-182]). This approach generalizes a result (and simplifies the proof) of P. K. Wong [3, Theorem 1.1].

Let $u(t)$ and $v(t)$ be two solutions of (1). If $u(t)$ and $v(t)$ are defined for $0 \leqq t<a \leqq+\infty$, then

$$
\begin{aligned}
u^{\prime}(t)-v^{\prime}(t)= & u^{\prime}(0)-v^{\prime}(0) \\
& +\int_{0}^{t}\left[f\left(r, u(r), u^{\prime}(r)\right)-f\left(r, v(r), v^{\prime}(r)\right)\right] d r .
\end{aligned}
$$

If $u(t)$ and $v(t)$ are defined for $0 \leqq t \leqq b<+\infty$, then

$$
\begin{aligned}
u(t)-v(t)= & u(0)-v(0)+\left[u^{\prime}(0)-v^{\prime}(0)\right] t \\
& \left.+\int_{0}^{t} \int_{0}^{s} f\left(r, u(r), u^{\prime}(r)\right)-f\left(r, v(r), v^{\prime}(r)\right)\right] d r d s .
\end{aligned}
$$

Theorem 1. If $u(t)$ and $v(t)$ are two proper solutions of (1) with $u(0)=v(0)=A>0, u^{\prime}(\infty)=v^{\prime}(\infty)=0$, then $u(t)=v(t)$ for all $t \geqq 0$.

Received by the editors November 1, 1965. 
Proof. Let $u(t)$ and $v(t)$ satisfy the hypotheses and assume $v^{\prime}(0)<u^{\prime}(0)$. Suppose there exists a $c>0$ such that $v(t)<u(t)$ and $v^{\prime}(t)<u^{\prime}(t)$ for $0<t<c$ and either $v(c)=u(c)$ or $v^{\prime}(c)=u^{\prime}(c)$. From (2) and (iv), $u^{\prime}(c)-v^{\prime}(c) \geqq u^{\prime}(0)-v^{\prime}(0)>0$; and from (3) and (iv), $u(c)-v(c) \geqq\left[u^{\prime}(0)-v^{\prime}(0)\right] c>0$. Therefore, $v(t)<u(t)$ and $v^{\prime}(t)<u^{\prime}(t)$ for $0 \leqq t<+\infty$ and $0=u^{\prime}(\infty)-v^{\prime}(\infty) \geqq\left[u^{\prime}(0)-v^{\prime}(0)\right]>0$, a contradiction. Thus, $v^{\prime}(0) \geqq u^{\prime}(0)$ - and likewise $u^{\prime}(0) \geqq v^{\prime}(0)$ - so $u(t)=v(t)$ for all $t \geqq 0$.

Lemma. Given $A>0, c>0$ there exists a $d(A, c)>0$ such that if $x(t)$ is a solution of (1) with $0<x(0) \leqq A$ and $x^{\prime}(0) \leqq-d$, then $x(t)=0$ for some $t \in(0, c)$.

Proof. Let $T=\{(t, x): 0 \leqq t \leqq c, 0 \leqq x \leqq A-t(A / c)\}$ and let $H$ be the hypotenuse of $T$. We will show that solutions satisfying the hypotheses do not cross $H$ for $0 \leqq t \leqq c$.

Let $M=\max \{f(t, x, 0):(t, x) \in T\}, M>0$ by (ii), and let $d=(A / c)$ $+M c$. Let $x(t)$ be a solution of (1) with $0<x(0) \leqq A$ and $x^{\prime}(0) \leqq-d$. For $t$ small, $x(t)$ lies in $T$ and below $H$. If $x(t)$ strikes $H$ for some $t \in(0, c]$, then there exists an $e \in(0, c)$ such that $x^{\prime}(e)=-(A / c)$, and $x^{\prime}(t)<-(A / c),(t, x(t)) \in T$ for $0 \leqq t<e$. Then

$$
\begin{aligned}
x^{\prime}(e) & =x^{\prime}(0)+\int_{0}^{e} f\left(s, x(s), x^{\prime}(s)\right) d s \\
& \leqq-(A / c)-M c+M e<-(A / c) .
\end{aligned}
$$

THEOREM 2. Given $A>0$ there exists exactly one proper solution, $x(t)$, of (1) such that $x(0)=A$ and $x^{\prime}(t)<0$ for all $t \geqq 0$.

Proof. Theorem 1 shows the uniqueness of such solutions.

Write (1) as a system

$$
\begin{aligned}
& x^{\prime}=y, \\
& y^{\prime}=f(t, x, y) ;
\end{aligned}
$$

we seek a solution, $(x(t), y(t))$, of (4) such that $x(0)=A>0, y(0)<0$, and $x(t)>0, y(t)<0$ for all $t \geqq 0$. We will now use the method and terminology of Ważewski. Let $T=\{(t, x, y): t \geqq 0, x>0, y<0\}$; $Q=\{(t, x, y): t \geqq 0, x>0, y=0\}$; and $R=\{(t, x, y): t \geqq 0, x=0, y<0\}$. For solutions of (4) with $t>0$, the set of egress of $T$ is $S=Q \cup R$ (by (i), the $t$-axis contains no points of egress). Every point in $Q$ is a point of strict egress since $y^{\prime}=f(t, x, 0)>0$ and every point in $R$ is a point of strict egress since $x^{\prime}=y<0$ on $R$. Thus, the set of egress equals the set of strict egress. 
Now let $X=\{(t, x, y): t=0, x=A,-d \leqq y \leqq 0\}$ (where $d$ is determined in the lemma); $Y=\{(t, x, y): t=0,0 \leqq x \leqq A, y=-d\}$; and $Z=X \cup Y$. Then $S \cap Z$ is a retract of $S$ but not of $Z$ and by Ważewski's theorem there exists a point $P=(0, a, b) \in Z$ such that the solution of (4) with $x(0)=a, y(0)=b$ remains in $T$ for all $t \geqq 0$. And by the lemma, $P \notin Y$.

\section{REFERENCES}

1. L. Cesari, Asymptotic behavior and stability problems in ordinary differential equations, Springer-Verlag, Berlin, 1959.

2. $\mathrm{T}$. Ważewski, Une méthode topologique de l'examen du phénomène asymptotique relativement aux equations différentielles ordinaires, Rend. Accad. Lincei 3 (1947), 210-215.

3. P. K. Wong, Existence and asymptotic behavior of proper solutions of a class of second-order nonlinear differential equations, Pacific J. Math. 13 (1963), 737-760.

Michigan State UnIVERSITY 